\title{
CONCENTRAÇÃO ECONÔMICA DO ESTADO DO MARANHÃO E DO \\ PRETENSO ESTADO DO “MARANHÃO DO SUL”, BRASIL, 2007 A 2010
}

\section{ECONOMIC CONCENTRATION OF MARANHAO STATE AND SUPPOSED "SOUTH MARANHAO" STATE, BRAZIL, 2007-2010}

\author{
Fernando Reis Babilônia ${ }^{1}$ \\ Alcido Elenor Wander ${ }^{2}$
}

\begin{abstract}
RESUMO
O objetivo deste estudo é analisar o grau de concentração da economia do estado do Maranhão contrapondo ao que poderia ser tal concentração no pretenso estado do "Maranhão do Sul". O indicador utilizado para levantar o grau de concentração da economia do estado foi o produto interno bruto (PIB) de todos os municípios no período de 2007 a 2010. A ferramenta computacional utilizada para a execução do levantamento foi o software Philcarto versão $5.73 \mathrm{e}$ a classificação escolhida para a realização do levantamento foi a Jenks. A economia do estado do Maranhão é altamente concentrada, em que apenas seis municípios $(2,76 \%)$ possuem uma participação média superior a 1\% do PIB, e 211 (97,24\%) municípios não atingem sequer 1\%. Já para o pretenso estado do "Maranhão do Sul" há uma situação de menor grau de concentração econômica; tem-se um número maior de municípios com participação média superior a $1 \%$ do PIB.
\end{abstract}

Palavras-chave: PIB. Philcarto. Municípios. Jenks.

\begin{abstract}
The aim of this study is to assess the degree of concentration of the economy of the State of Maranhão in the Northeast region opposed to what could be such a concentration on the supposed State of "South Maranhão". The indicator used to raise the degree of concentration of the economy of the State was the gross domestic product (GDP) of all municipalities in the period from 2007 to 2010. The computational tool used for the execution of the survey was the software Philcarto version 5.73 and the classification chosen for the realization of the survey was to Jenks. The economy of the State of Maranhão in the Northeast region is highly concentrated, where only six municipalities $(2.76 \%)$ have an average attendance in excess of 1\% of GDP, and 211 (97.24) municipalities do not reach even 1\%. Already for the would-be State of "South Maranhão" there is a situation of a lesser degree of economic concentration, has a larger number of municipalities with participation exceeding average $1 \%$ of GDP.
\end{abstract}

Keywords: GDP. Philcarto. Municipalities. Jenks.

\footnotetext{
${ }^{1}$ Faculdades Alves Faria (ALFA). Economista. Discente do Programa de Pós-graduação em Desenvolvimento Regional das Faculdades Alves Faria (ALFA) - Av. Perimetral Norte, 4129, Vila Joao Vaz, Goiânia, GO - CEP: 74445-190. E-mail: babyllonia@hotmail.com

${ }^{2}$ Faculdades Alves Faria (ALFA). Graduação em Agronomia pela Universidade de Kassel (1996), mestrado em Ciências Agrárias dos Trópicos e Subtrópicos (1998) e doutorado em Ciências Agrárias (2002), ambos na Georg August Universität Göttingen. Professor titular das Faculdades ALFA. Av. Perimetral Norte, 4129, Vila Joao Vaz, Goiânia, GO - CEP: 74445-190. E-mail: alcido.wander@alfa.br
} 


\section{Introdução}

A concentração econômica é extremamente prejudicial ao desenvolvimento econômico de um país, de um estado ou de uma região. O Brasil é caracterizado por uma forte concentração de renda, onde poucos detêm grande parte da renda gerada, e isso impede que aconteça um avanço real de toda a sociedade.

O estado do Maranhão é composto por 217 municípios, cuja maior parte deles tem uma participação muito pequena na composição do produto interno bruto (PIB) do estado. O estado sempre figura entre os piores quando se aborda indicadores sociais, tais como nível educacional, saúde, segurança e infraestrutura básica, que, em parte, contribuem para um dos piores índices de desenvolvimento humano (IDH) do país. Há uma disputa na "lanterna" entre Maranhão, Piauí e Alagoas pela última posição. Há, portanto, um grande número de demandas sociais que poderiam ser minimizadas através de um desempenho mais igualitário das economias dos municípios, com uma melhor distribuição de riquezas.

Há também uma demanda antiga, proposta por vários municípios do "sul" do estado do Maranhão, para o desmembramento do restante do estado, criando, assim, o pretenso Estado do "Maranhão do Sul". Tal estado seria composto por 49 municípios localizados na região sul do Maranhão. Uma das justificativas para a criação do estado é o fato de que o governo do Maranhão, ao longo dos tempos, nunca realmente se preocupou em desenvolver tal região do estado deixando-a à própria sorte, assim a divisão seria benéfica, pois traria para perto as decisões governamentais, priorizando a resolução dos problemas locais.

Nesse sentido, o objetivo deste estudo é analisar o grau de concentração da economia do estado do Maranhão contrapondo ao que poderia ser tal concentração no pretenso estado do "Maranhão do Sul". E, ao fim do estudo, através dos resultados, discutir possíveis alternativas para a redução da possível concentração econômica existente.

\section{Metodologia}

Para realizar o levantamento do grau de concentração da economia do Maranhão e do "Maranhão do Sul" foi utilizado o método de Sistema de Informação Geográfica (SIG). Os SIGs podem dar uma contribuição importante para conhecer e compreender a 
organização territorial, nos diversos níveis de análise e proposta de intervenção (WANDER, 2010).

O indicador utilizado para levantar o grau de concentração da economia do estado foi o Produto Interno Bruto (PIB) de todos os municípios no período de 2007 a 2010. Essa definição se deve ao fato de que se pretendia verificar se nesse período houve alguma alteração no PIB dos municípios, reduzindo ou aumentando o grau de concentração. $\mathrm{O}$ levantamento foi feito através dos percentuais de participação do PIB dos municípios em relação ao total do PIB do estado do Maranhão, e para o pretenso estado "Maranhão do Sul" levou-se em consideração o percentual do PIB dos 49 municípios que fariam parte do estado em relação ao que seria seu PIB total.

A ferramenta computacional utilizada para a execução do levantamento foi o software Philcarto versão 5.73 (WANIEZ, 2014), que possibilita realizar a análise através de várias formações de classes. A classificação escolhida para a realização do levantamento foi a Jenks. Conforme Girardi (2007), a "classificação de Jenks visa minimizar a variância intraclasses e maximizar a variância interclasses, produzindo, assim, classes homogêneas (clusters)". Assim, torna-se possível classificar os municípios de acordo com a participação de cada um em relação ao PIB total do estado seja ele o Maranhão ou "Maranhão do Sul".

A base de dados utilizados para a realização do levantamento foi o IPEADATA do IPEA (2014), que contêm informações sem qualquer tipo de viés.

\section{Resultados e discussão}

Como demonstrado na tabela 1, o PIB do "Maranhão do Sul" representa, na média, R \$ 4.368.935,01 (22,67\%) do PIB do Maranhão para o período avaliado. Apenas São Luís apresenta, na média, um PIB de R\$ 7.473.748,85 (38,78\%) do PIB do estado, para o mesmo período.

Tabela 1 - PIB (R\$ bilhões) do Maranhão e do "Maranhão do Sul", 2007-2010

\begin{tabular}{l|c|c|c|c}
\multicolumn{1}{c|}{ Estado } & $\mathbf{2 0 0 7}$ & $\mathbf{2 0 0 8}$ & \multicolumn{1}{c}{$\mathbf{2 0 0 9}$} & \multicolumn{1}{c}{$\mathbf{2 0 1 0}$} \\
\hline Maranhão & $17.723 .113,37$ & $19.921 .141,24$ & $19.246 .396,33$ & $20.193 .159,52$ \\
\hline "Maranhão do Sul" & $4.098 .449,19$ & $4.634 .531,92$ & $4.358 .004,75$ & $4.384 .754,19$
\end{tabular}

Fonte: IPEADATA, elaborada pelos autores. 
Pela Tabela 2, é possível identificar os municípios que fariam parte do estado do "Maranhão do Sul", assim como verificar o PIB nominal e percentual de participação de cada um desses municípios para a composição do PIB total.

Tabela 2 - PIB (R\$ milhões) dos municípios do "Maranhão do Sul”, 2007-2010

\begin{tabular}{|c|c|c|c|c|c|c|c|c|}
\hline Município & 2007 & $\%$ PIB & 2008 & $\%$ PIB & 2009 & $\%$ PIB & 2010 & $\%$ PIB \\
\hline Açailândia & $1.004 .592,27$ & 24,51 & $914.202,95$ & 19,73 & $628.313,68$ & 14,42 & $583.278,24$ & 13,30 \\
\hline Alto Parnaíba & $20.333,61$ & 0,50 & $40.783,75$ & 0,88 & $46.966,10$ & 1,08 & $44.024,84$ & 1,00 \\
\hline Amarante do Maranhão & $60.417,93$ & 1,47 & $69.310,06$ & 1,50 & $63.492,13$ & 1,46 & $64.278,53$ & 1,47 \\
\hline Arame & $42.361,63$ & 1,03 & $47.776,15$ & 1,03 & $46.995,18$ & 1,08 & $51.701,64$ & 1,18 \\
\hline Balsas & $351.177,47$ & 8,57 & $464.198,30$ & 10,02 & $541.352,49$ & 12,42 & $491.909,07$ & 11,22 \\
\hline Barra do Corda & $200.835,22$ & 4,90 & $224.338,63$ & 4,84 & $189.595,63$ & 4,35 & $220.354,82$ & 5,03 \\
\hline Benedito Leite & $7.444,60$ & 0,18 & $8.784,75$ & 0,19 & $8.811,98$ & 0,20 & $9.184,64$ & 0,21 \\
\hline Bom Jesus das Selvas & $53.683,28$ & 1,31 & $64.490,37$ & 1,39 & $58.832,91$ & 1,35 & $75.745,63$ & 1,73 \\
\hline Buriticupu & $119.700,46$ & 2,92 & $166.299,69$ & 3,59 & $120.265,43$ & 2,76 & $126.453,95$ & 2,88 \\
\hline Buritirana & $19.653,46$ & 0,48 & $20.709,93$ & 0,45 & $23.554,52$ & 0,54 & $23.217,12$ & 0,53 \\
\hline Campestre do Maranhão & $40.896,63$ & 1,00 & $37.036,41$ & 0,80 & $33.083,12$ & 0,76 & $39.147,55$ & 0,89 \\
\hline Carolina & $44.997,08$ & 1,10 & $57.112,67$ & 1,23 & $56.742,38$ & 1,30 & $58.480,60$ & 1,33 \\
\hline Cidelândia & $73.167,31$ & 1,79 & $55.816,52$ & 1,20 & $39.539,49$ & 0,91 & $48.291,98$ & 1,10 \\
\hline Davinópolis & $17.128,24$ & 0,42 & $16.369,61$ & 0,35 & $17.087,79$ & 0,39 & $19.082,11$ & 0,44 \\
\hline Estreito & $70.301,80$ & 1,72 & $89.432,58$ & 1,93 & $128.168,39$ & 2,94 & $156.428,29$ & 3,57 \\
\hline Feira Nova do Maranhão & $12.057,30$ & 0,29 & $15.488,19$ & 0,33 & $15.612,57$ & 0,36 & $15.466,31$ & 0,35 \\
\hline Fernando Falcão & $16.701,34$ & 0,41 & $20.217,02$ & 0,44 & $17.835,05$ & 0,41 & $18.791,50$ & 0,43 \\
\hline Formosa da Serra Negra & $29.415,70$ & 0,72 & $29.946,88$ & 0,65 & $31.335,41$ & 0,72 & $33.299,81$ & 0,76 \\
\hline Fortaleza dos Nogueiras & $29.834,47$ & 0,73 & $42.945,44$ & 0,93 & $38.771,45$ & 0,89 & $38.297,18$ & 0,87 \\
\hline Governador Edison Lobão & $39.797,94$ & 0,97 & $30.564,42$ & 0,66 & $28.949,46$ & 0,66 & $36.246,69$ & 0,83 \\
\hline Grajaú & $109.780,64$ & 2,68 & $130.565,84$ & 2,82 & $133.902,33$ & 3,07 & $148.877,27$ & 3,40 \\
\hline Imperatriz & $875.791,38$ & 21,37 & $901.063,23$ & 19,44 & $966.352,78$ & 22,17 & $945.771,99$ & 21,57 \\
\hline Itaipava do Grajaú & $15.374,05$ & 0,38 & $18.130,74$ & 0,39 & $21.517,10$ & 0,49 & $19.846,89$ & 0,45 \\
\hline Itinga do Maranhão & $115.476,46$ & 2,82 & $79.245,78$ & 1,71 & $66.540,37$ & 1,53 & $92.088,06$ & 2,10 \\
\hline Jenipapo dos Vieiras & $22.961,87$ & 0,56 & $24.719,66$ & 0,53 & $24.946,89$ & 0,57 & $22.959,06$ & 0,52 \\
\hline João Lisboa & $39.542,60$ & 0,96 & $42.312,79$ & 0,91 & $43.424,58$ & 1,00 & $44.058,14$ & 1,00 \\
\hline Lajeado Novo & $11.734,34$ & 0,29 & $13.638,24$ & 0,29 & $15.401,99$ & 0,35 & $14.779,51$ & 0,34 \\
\hline Loreto & $24.127,42$ & 0,59 & $32.701,20$ & 0,71 & $40.430,87$ & 0,93 & $40.450,65$ & 0,92 \\
\hline Mirador & $36.524,27$ & 0,00 & $44.581,72$ & 0,00 & $46.885,52$ & 0,00 & $53.892,41$ & 0,00 \\
\hline Montes Altos & $15.147,85$ & 0,37 & $15.859,25$ & 0,34 & $16.917,34$ & 0,39 & $16.205,70$ & 0,37 \\
\hline Nova Colinas & $8.062,58$ & 0,20 & $10.456,44$ & 0,23 & $11.063,36$ & 0,25 & $12.066,32$ & 0,28 \\
\hline Nova Iorque & $7.789,96$ & 0,19 & $7.746,66$ & 0,17 & $8.072,78$ & 0,19 & $7.885,98$ & 0,18 \\
\hline Pastos Bons & $20.986,91$ & 0,51 & $26.384,02$ & 0,57 & $27.408,38$ & 0,63 & $27.671,12$ & 0,63 \\
\hline Porto Franco & $83.802,50$ & 2,04 & $101.329,76$ & 2,19 & $102.228,86$ & 2,35 & $96.526,55$ & 2,20 \\
\hline Riachão & $47.284,24$ & 1,15 & $71.929,36$ & 1,55 & $73.029,93$ & 1,68 & $64.954,53$ & 1,48 \\
\hline Ribamar Fiquene & $16.877,87$ & 0,41 & $19.534,11$ & 0,42 & $18.443,61$ & 0,42 & $20.462,92$ & 0,47 \\
\hline Sambaíba & $19.311,11$ & 0,47 & $55.829,18$ & 1,20 & $48.552,97$ & 1,11 & $40.288,83$ & 0,92 \\
\hline São Domingos do Azeitão & $14.709,92$ & 0,36 & $29.531,99$ & 0,64 & $34.211,38$ & 0,79 & $26.866,86$ & 0,61 \\
\hline São Félix de Balsas & $6.182,54$ & 0,15 & $8.958,68$ & 0,19 & $9.201,44$ & 0,21 & $8.323,59$ & 0,19 \\
\hline São Francisco do Brejão & $18.550,87$ & 0,45 & $19.982,49$ & 0,43 & $22.087,67$ & 0,51 & $21.833,22$ & 0,50 \\
\hline São João do Paraíso & $25.061,75$ & 0,61 & $29.841,06$ & 0,64 & $24.378,20$ & 0,56 & $23.156,06$ & 0,53 \\
\hline São Pedro da Água Branca & $26.927,96$ & 0,66 & $49.393,00$ & 1,07 & $31.533,51$ & 0,72 & $46.611,54$ & 1,06 \\
\hline São Pedro dos Crentes & $9.134,88$ & 0,22 & $12.291,08$ & 0,27 & $13.125,72$ & 0,30 & $12.774,63$ & 0,29 \\
\hline São Raimundo das Mangabeiras & $102.846,80$ & 2,51 & $199.440,76$ & 4,30 & $180.885,10$ & 4,15 & $191.698,31$ & 4,37 \\
\hline Senador La Rocque & $37.669,56$ & 0,92 & $41.136,64$ & 0,89 & $42.439,31$ & 0,97 & $42.314,72$ & 0,97 \\
\hline
\end{tabular}




\begin{tabular}{l|c|c|c|c|c|c|c|c} 
Sítio Novo & $27.410,87$ & 0,67 & $28.920,69$ & 0,62 & $30.599,70$ & 0,70 & $32.260,67$ & 0,74 \\
\hline Sucupira do Norte & $12.899,60$ & 0,31 & $14.339,52$ & 0,31 & $15.192,61$ & 0,35 & $16.830,91$ & 0,38 \\
\hline Tasso Fragoso & $41.518,92$ & 1,01 & $136.506,22$ & 2,95 & $122.164,85$ & 2,80 & $103.393,22$ & 2,36 \\
\hline Vila Nova dos Martírios & $50.461,68$ & 1,23 & $52.337,47$ & 1,13 & $31.760,44$ & 0,73 & $36.224,04$ & 0,83 \\
\hline \multicolumn{1}{c|}{ TOTAL PIB } & $4.098 .449,19$ & 100,00 & $4.634 .531,92$ & 100,00 & $4.358 .004,75$ & 100,00 & $4.384 .754,19$ & 100,00
\end{tabular}

Fonte: IPEADATA, elaborado pelos autores (2014).

Como a Figura 1 demonstra, há um altíssimo grau de concentração da economia maranhense, em que apenas seis municípios $(2,76 \%)$ possuem uma participação média de mais de $2 \%$ do PIB, e destes a capital São Luís sozinha tem uma participação de 38,95\% do PIB do estado do Maranhão em 2007. Os outros 211 municípios do estado têm uma participação média inferior a 1\%, dos quais 21 municípios possuem uma média de $0,71 \%$ do PIB e 190 , uma média de $0,16 \%$. Tem-se, assim, um estado com grande desigualdade, em que a riqueza se concentra em poucos municípios.

Figura 1 - Participação dos municípios no PIB (\%) do Maranhão, 2007

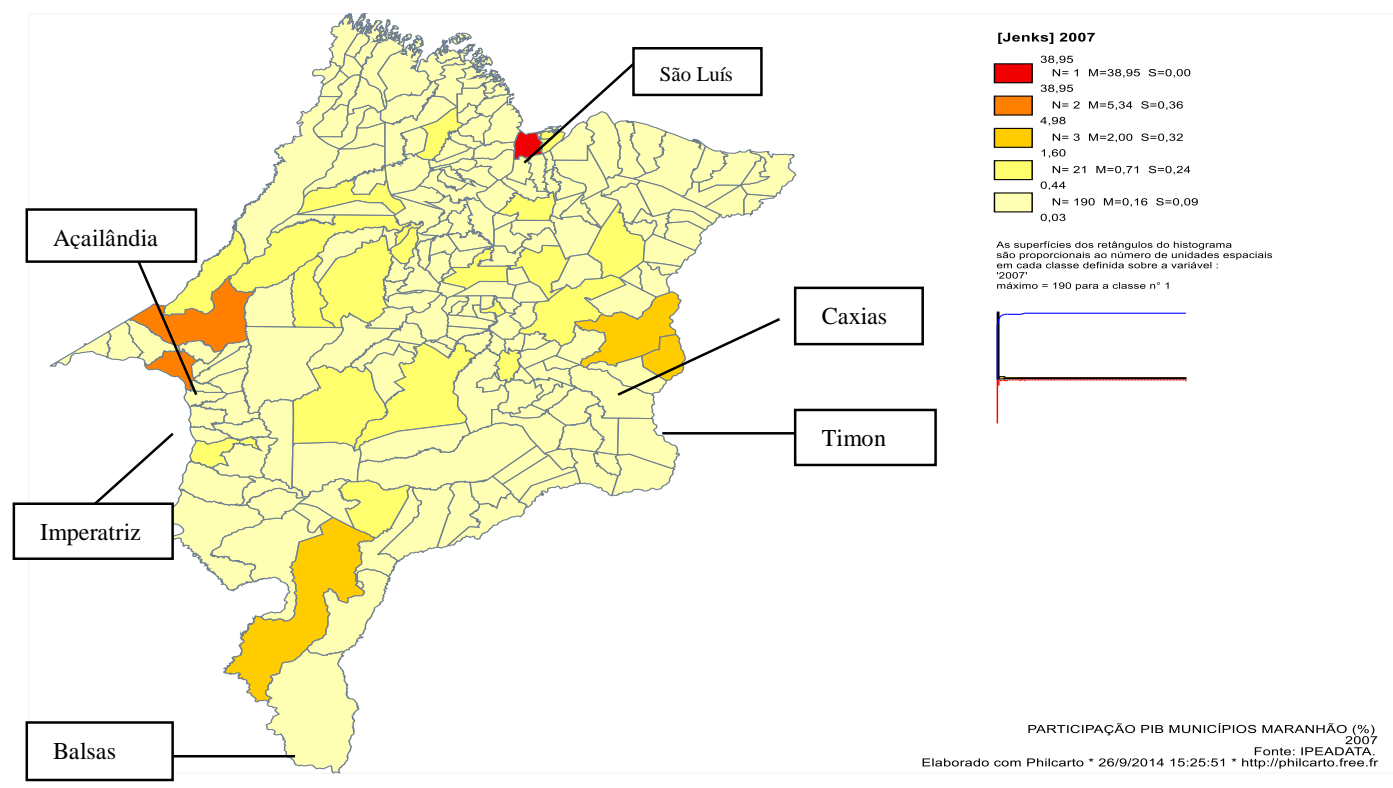

Fonte: elaborada pelos autores (2014).

A Figura 2 refere-se ao que seria o pretenso estado do "Maranhão do Sul", considerando o PIB de 2007. Percebe-se que o grau de concentração da economia seria reduzido, pois 12 municípios $(24,49 \%)$ teriam uma participação média acima de 2,24\% do PIB desse pretenso novo estado e os outros 37 municípios teriam uma participação média de $0,59 \%$. Observa-se que mesmo os municípios com uma participação menor estão em condições "melhores" do que os municípios com piores médias do estado do Maranhão. 
Figura 2 - Participação dos municípios no PIB (\%) do "Maranhão do Sul”, 2007

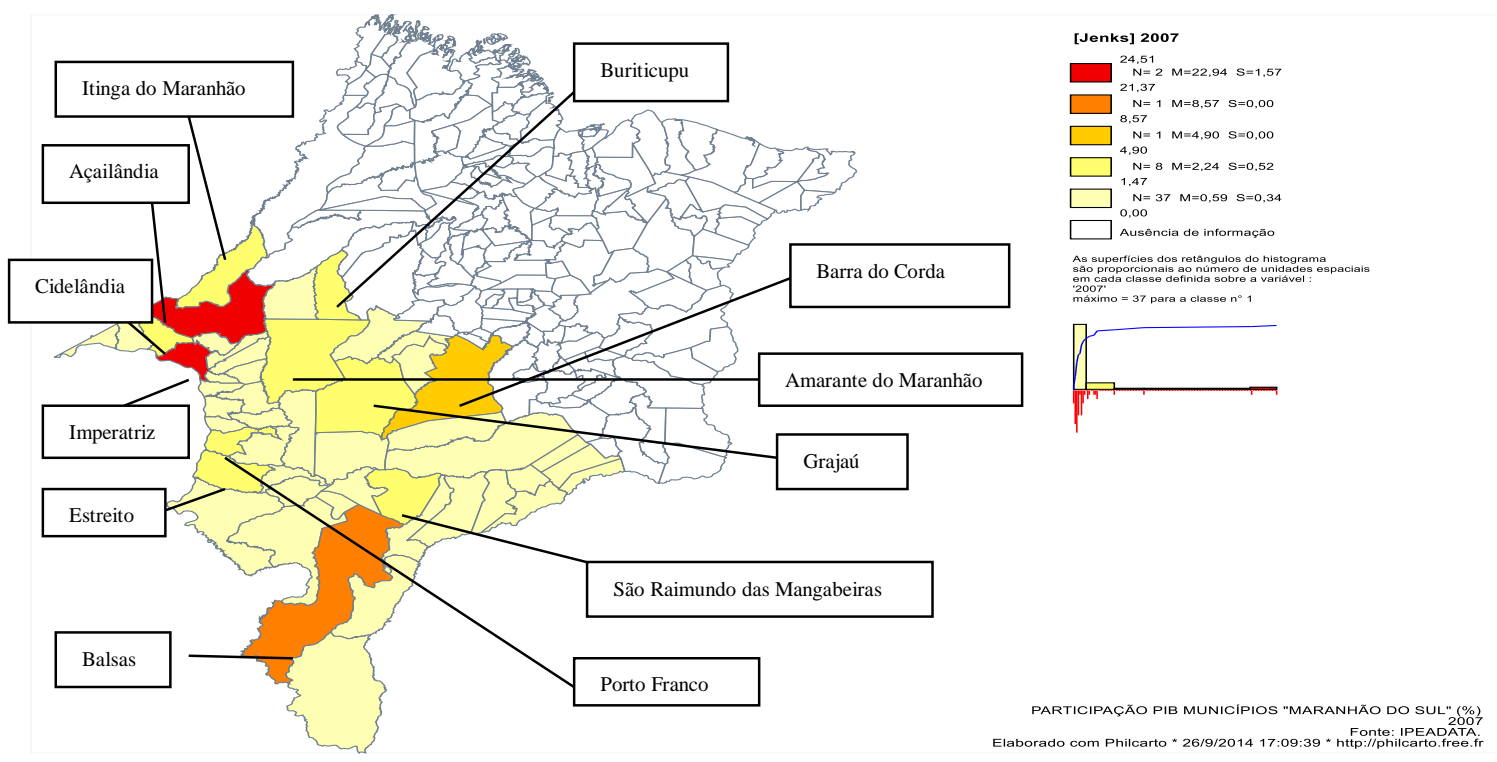

Fonte: elaborada pelos autores (2014).

Verificando a Figura 3, observa-se que em 2008, para o estado do Maranhão, não há variação em relação ao ano de 2007, ou seja, apenas seis municípios concentram grande parte do PIB do estado com participação média acima de $1,91 \%$, e o restante dos municípios possui uma participação média inferior a $0,81 \%$ do PIB.

Figura 3 - Participação dos municípios no PIB (\%) do Maranhão, 2008
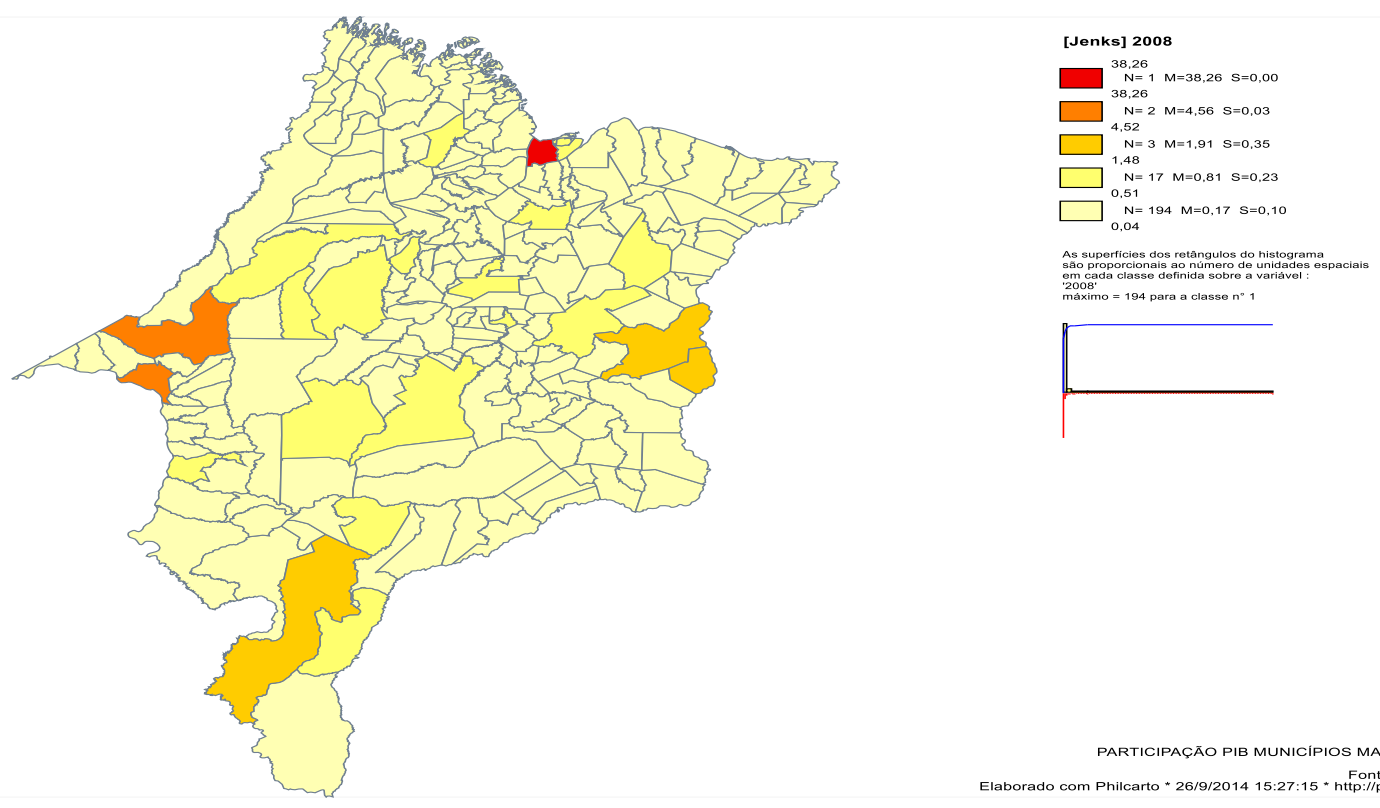

Fonte: elaborada pelos autores (2014). 
Em relação à Figura 4, verifica-se que para o estado do "Maranhão do Sul" há algumas modificações em 2008. Vinte municípios (40,82\%) apresentam uma participação média superior a $1,43 \%$ do PIB, nesse sentido, houve uma melhora no que se refere à concentração da economia nessa região.

Figura 4 - Participação dos municípios no PIB (\%) do "Maranhão do Sul”, 2008
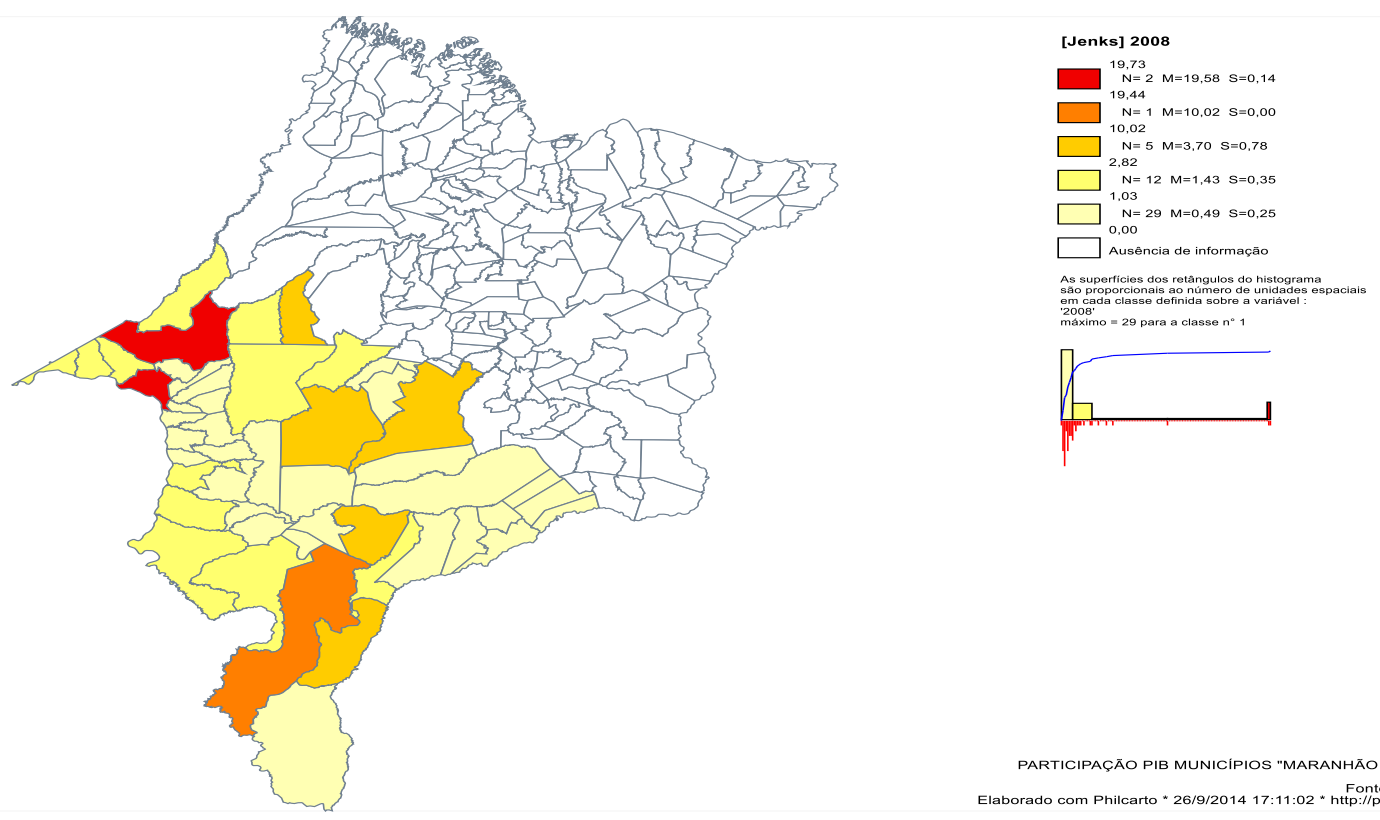

Fonte: elaborada pelos autores (2014).

Novamente é possível verificar, através dos dados consolidados nas Figuras 5 e 6, que para o estado do Maranhão não há modificação em relação às principais economias. Os mesmos seis municípios ainda são os grandes representantes do estado em termos econômicos. Já para o pretenso estado do "Maranhão do Sul” há novamente um acréscimo de municípios com participação média de mais de 1,18\% do PIB em 2009. Esse número foi para $23(46,94 \%)$ municípios, reduzindo ainda mais o grau de concentração da economia na região. 
Figura 5 - Participação dos municípios no PIB (\%) do Maranhão, 2009
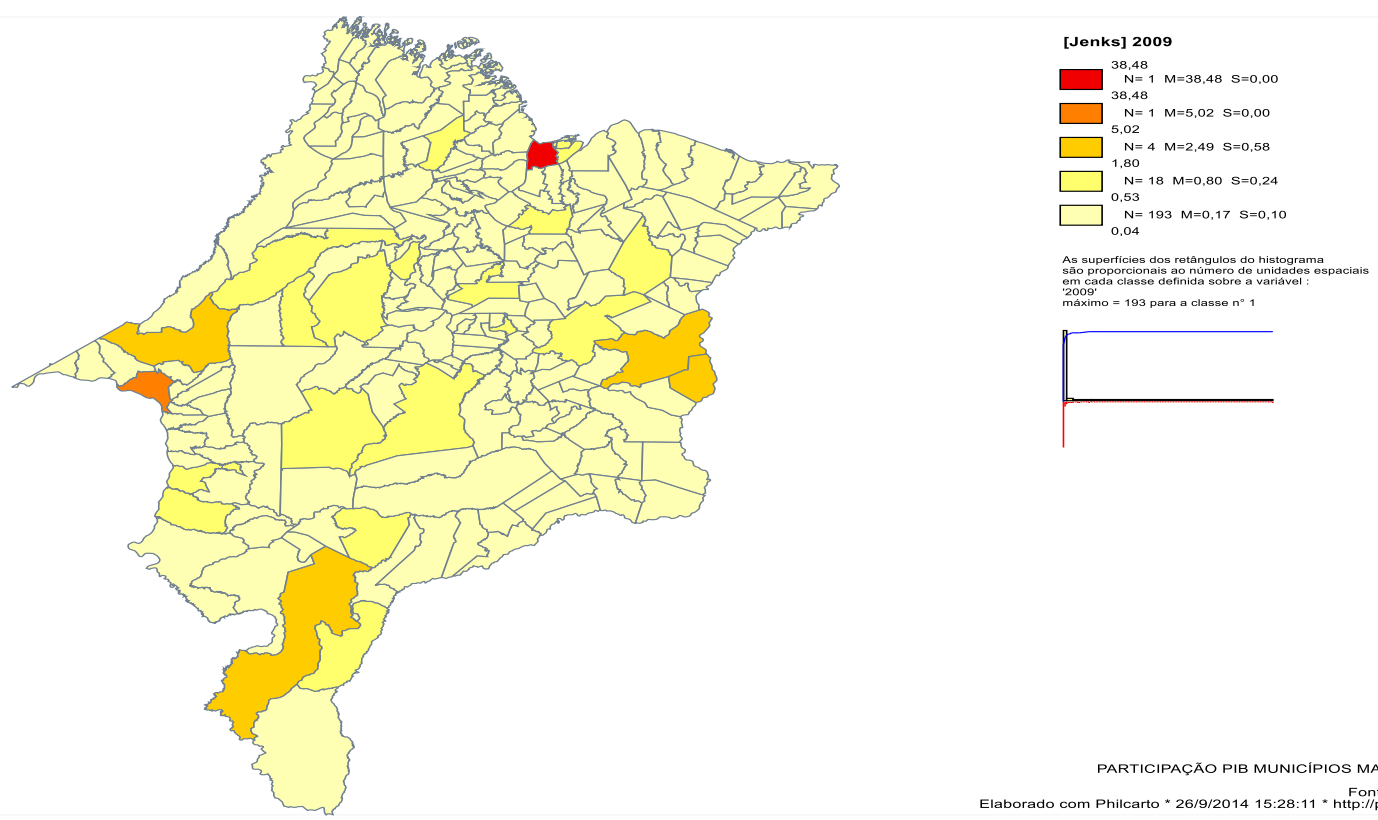

Fonte: elaborada pelos autores (2014).

Figura 6 - Participação dos municípios no PIB (\%) do "Maranhão do Sul”, 2009
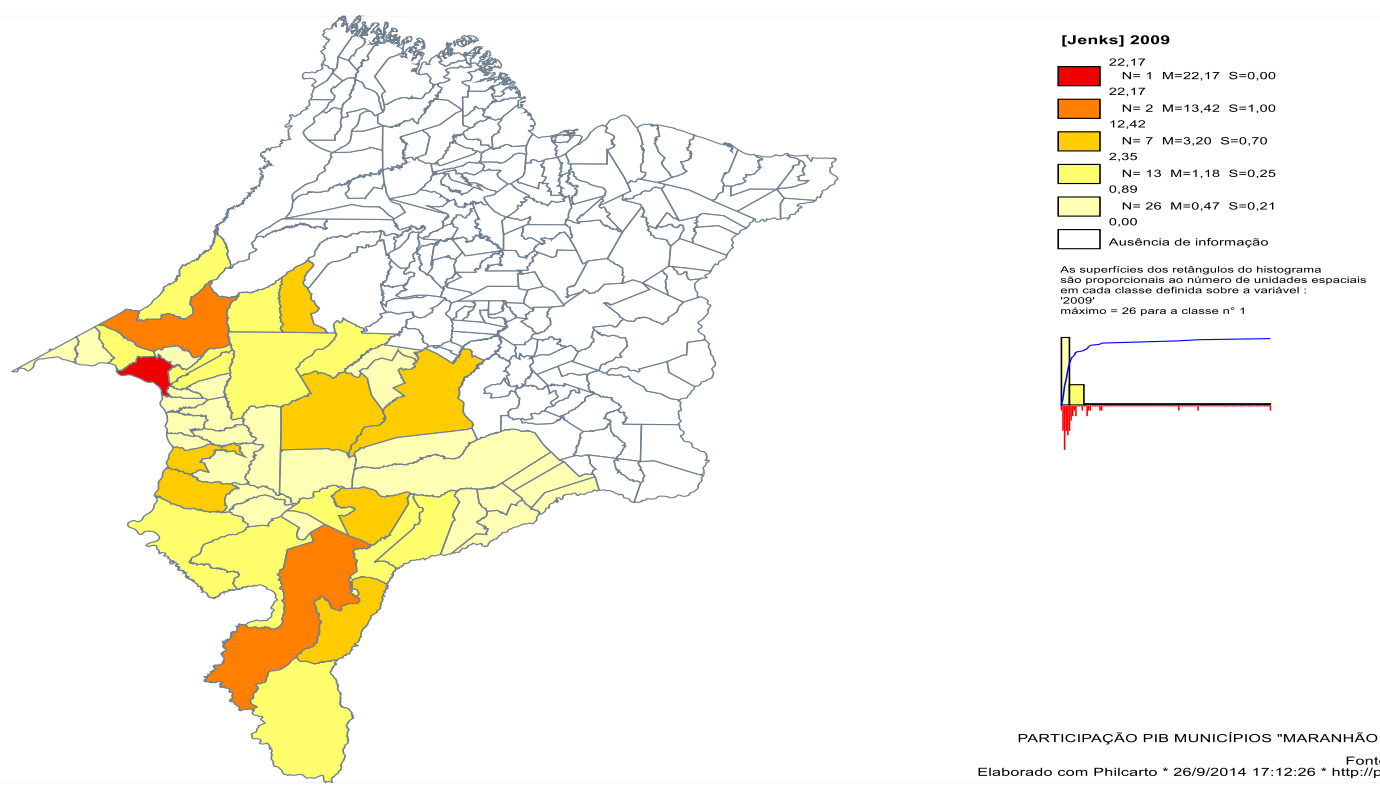

Fonte: elaborada pelos autores (2014).

No estado do Maranhão não há modificação de cenário em 2010 (Figura 7), ou seja, desde 2007 (Figuras 1, 3 e 5) apenas seis municípios possuem uma participação média acima de $1 \%$ do PIB, o que denota uma economia com alto grau de concentração. Em 2010 o pretenso estado do "Maranhão do Sul” tem uma pequena queda no número de 
municípios que apresentam uma participação média superior a 1\% do PIB. Em 2010 o número foi de $15(30,61 \%)$ municípios (Figura 8).

Figura 7 - Participação dos municípios no PIB (\%) do Maranhão, 2010
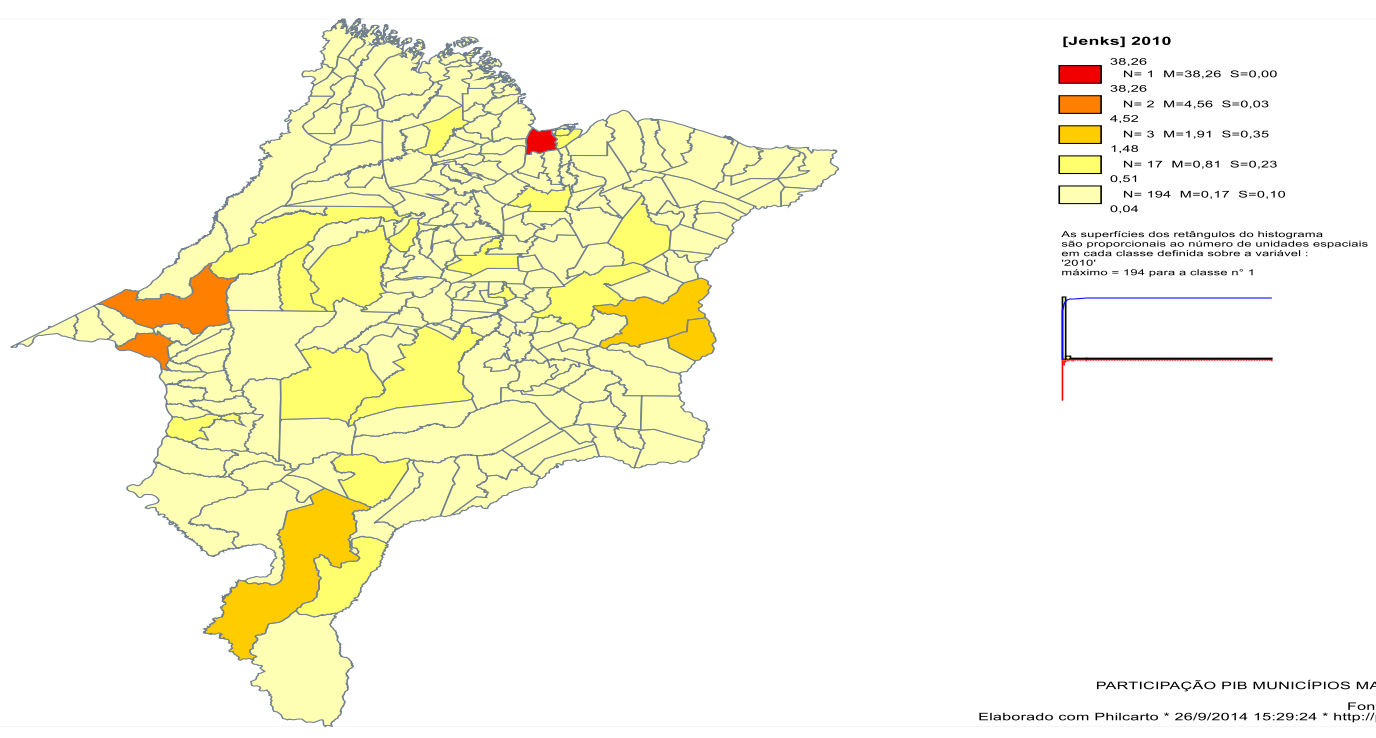

Fonte: elaborada pelos autores (2014).

Figura 8 - Participação dos municípios no PIB (\%) do "Maranhão do Sul”, 2010
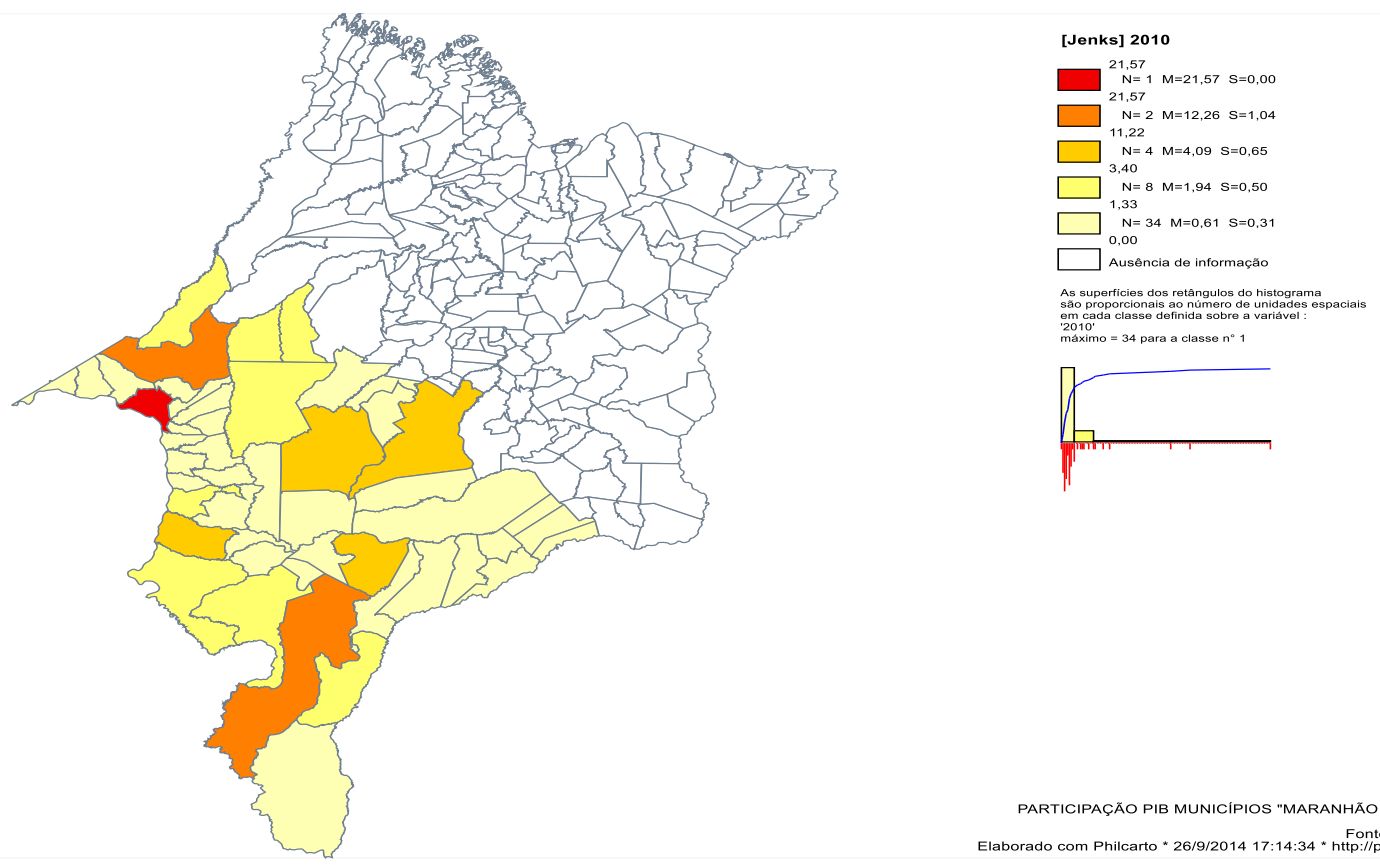

Fonte: elaborada pelos autores (2014).

A economia do estado do Maranhão é altamente concentrada, em que apenas seis municípios $(2,76 \%)$ possuem uma participação média superior a 1\% do PIB, e 211 (97,24\%) municípios do Maranhão não atingem sequer $1 \%$ do PIB, um dado 
extremamente preocupante, pois o Estado possui grandes potencialidades econômicas assim como grandes demandas sociais. Ainda nessa linha, observa-se que mesmo entre os seis municípios que possuem uma participação média superior a 1\% do PIB há grandes diferenças, principalmente em relação ao primeiro colocado, a capital São Luís, que sozinha representou, no período de 2007 a 2010, uma média de 38,49\% do PIB do estado, o que em termos nominais foi $\mathrm{R} \$ 7.473 .748,85$. O segundo colocado, o município de Imperatriz, fica muito abaixo da capital, e para o mesmo período teve uma média de participação no PIB de 4,76\%, com cerca de R \$922.244,84. Tal concentração econômica pode ser um dos fatores determinantes dos altos índices de pobreza apresentados pelo estado.

É importante mencionar as consequências que a concentração econômica provoca. O Maranhão possui um dos piores índices de desenvolvimento humano (IDH) do país. Em 1991 ficou na última posição dentre as 27 unidades da federação; em 2000 e 2010 ficou na penúltima colocação, perdendo apenas para o estado de Alagoas. A variável do IDH que mais preocupa no caso do Maranhão é a educação, que em todos os anos teve o pior desempenho. É possível credenciar ao alto índice de concentração o fato de não se ter o mesmo volume de recursos destinados à educação no estado. Os seis municípios "privilegiados" que possuem uma participação média acima de 1\% do PIB têm um volume maior de investimento em educação, o que faz com que a condição de "privilegiados" continue ao longo dos anos.

Já para o pretenso estado do "Maranhão do Sul” há uma situação de menor grau de concentração econômica; tem-se um número maior de municípios com participação média superior a $1 \%$ do PIB. Isso não quer dizer que não há problemas, é necessário que se trabalhe muito para que um maior número de municípios tenha a mesma condição de investimentos. Ainda é possível observar que, contrariamente ao que se viu em relação ao Maranhão, não houve alterações no grau de concentração no período pesquisado. No estado do "Maranhão do Sul" houve evoluções no número de municípios que possuíam uma participação média superior a 1\% do PIB, apenas em 2010 houve uma pequena queda, que pode ser devido à alguma crise específica. A dinâmica da economia do "Maranhão do Sul" é, portanto, diferente da dinâmica da economia do Maranhão. A divisão do estado proporcionaria, portanto, uma redução da concentração econômica. $O$ novo estado com seus 49 municípios teria uma melhor distribuição de riquezas. Haveria, 
ao contrário do que se tem no atual estado, uma participação maior de municípios na composição do PIB.

Portanto, ao fim do estudo, foi possível observar que o estado do Maranhão tem uma economia altamente concentrada, em que apenas 2,76\% dos municípios possuem uma participação média superior a $1 \%$ do PIB, e esse cenário não se altera ao longo do período analisado (2007-2010). O estado do "Maranhão do Sul" apresenta um grau de concentração econômica menor, em que um número maior de municípios possui uma participação média superior a $1 \%$ do PIB e para o período analisado há evolução nessa participação. Há, portanto, para o Maranhão, uma falta de dinâmica em relação à concentração da economia, e para o estado do "Maranhão do Sul" há dinâmica, ou seja, ao longo do período há mudança no cenário econômico que permite uma maior participação de outros municípios no "bolo" da economia.

\section{Considerações finais}

Esses dados do PIB dos municípios do estado do Maranhão de 2007 a 2010 demonstram a grande concentração da economia no estado. Em um cenário de criação do pretenso estado do "Maranhão do Sul", a concentração da economia seria bem menor nesse novo estado.

\section{REFERÊNCIAS}

GIRARDI, E. P. Manual de utilização do programa Philcarto. Versão 4.xx para Windows. 17 abr. 2007.

INSTITUTO DE PESQUISA ECONÔMICA APLICADA (IPEA). Base de dados IPEADATA: PIB municipal a preços constantes. Disponível em: <http://www.ipeadata.gov.br>. Acesso em: 24 set. 2014.

PROGRAMA DAS NAÇÕES UNIDAS PARA O DESENVOLVIMENTO (PNUD). Ranking IDH estados. Disponível em: <http://www.atlasbrasil.org.br/2013/pt/ranking>. Acesso em: 27 set. 2014.

WANDER, A. E. Métodos e técnicas de análise regional. In: NEGRET, F. N. (Org.). Desenvolvimento regional e gestão de empreendimentos: Conceitos, métodos, instrumentos e estratégias. Goiânia: Faculdades Alves Faria, 2010. p. 1-15. 
WANIEZ, P. Philcarto for Windows. Versão 5.73 (31/03/2014). Disponível em <http://philcarto.free.fr>. Acesso em: 22 set. 2014.

Recebimento dos originais: $15 / 11 / 2014$

Aceitação para publicação: 28/08/2014 